\title{
A numerical study on effect of corner radius and Reynolds number on fluid flow over a square cylinder
}

\author{
PRASENJIT DEY* and AJOY K R DAS \\ Department of Mechanical Engineering, National Institute of Technology Agartala, Agartala 799055, India \\ e-mail: pdey.me@nita.ac.in; deyprasenjitnita@gmail.com
}

MS received 5 January 2016; revised 6 October 2016; accepted 19 January 2017

\begin{abstract}
The behaviour of the fluid flowing over a square cylinder with rounded edges subjected to an upstream steady laminar flow was investigated numerically. Here, the commercial CFD software Fluent was used. A two-dimensional steady laminar flow has been investigated numerically at low Reynolds number $5 \leq \operatorname{Re} \leq 45$, different corner radii $(r=0.50,0.51,0.54,0.59,0.64$ and 0.71$)$ and blockage 0.05 . The effects of the parameters such as Reynolds number and corner radius on the drag and laminar boundary layer have been studied for the first time. The results are shown in the form of drag coefficient, boundary layer and pressure coefficient on the cylinder surface. It is found that the boundary layer thickness and the displacement thickness decrease with decreasing of the corner radius for a particular Re and also the boundary layer profile shifted downwards on decreasing Re.
\end{abstract}

Keywords. Corner radius; boundary layer; displacement thickness; velocity profile; CFD.

\section{Introduction}

Over the last many years, the flow around slender cylindrical bluff bodies has been the subject of intense research, mainly owing to the engineering significance of structural design, flow-induced vibration and heat exchanger tube bundle [1]. The incompressible flow past a stationary cylinder is a very important problem in fluid mechanics. The vast majority of these studies have been carried out for the flow past a circular cylinder and sharp-edged square and triangular cylinder. Based on a combination of numerical, theoretical and experimental studies, different flow regimes for the square cylinder have been identified in the literature depending upon the value of the Reynolds number [2-10]. The main flow regime reported to date is the creeping flow region in which no flow separation takes place at the surface of the cylinder $(\operatorname{Re} \leq 1)$. At low Reynolds numbers $(2$ $<\operatorname{Re}<60$ ), a closed steady recirculation region characterized by the formation of two symmetric vortices behind the bluff body is observed. Also, most of the studies with circular cylinder have been both numerical and experimental [11-17]. However, the rounded corner square cylinder is also very important to study the flow behaviour and to reduce the drag force and the vortex shedding transverse force $[18,19]$.

An experimental study on the effects of the corner radius of a square prism has been conducted by $\mathrm{Hu}$ et al [20]. They took four numbers of rounded corner values as 0

*For correspondence (square cylinder), $0.157,0.236$ and 0.5 (circular cylinder) and concluded that the roundness has large effect on the fluid flow characteristics. The static pressure distributions on a group of cylinders with either square or rectangular cross-section having rounded corners have been studied experimentally in a subsonic wind tunnel by Mandal and Faruk [21]. They studied the effect of the corner radius of a square and rectangular cylinder on the fluid flow and made the conclusion that the roundness can efficiently reduce the drag coefficient. Carassale and Freda [22, 23] experimentally studied the influence of the corner shaping (with two roundness values) and turbulence intensity on the aerodynamic stability of a square cylinder.

A study on the hydrodynamic-thermal boundary layer around a circular cylinder in confined flow at different blockages has been carried out by Ozalp and Dincer [24]. They found that the thinning of thermal and hydrodynamic boundary layer is directly proportional to blockage. The same authors [25] also studied the fluid flow and heat-mass transfer characteristics on laminar boundary layer development around a circular cylinder for the same blockage. Lin and Zhang [26] numerically simulated the wave-induced laminar boundary layers and reported that the influence of the outside flow on the velocity profile and bed shear stress distribution in the boundary layer is significant for nonlinear shallow water waves. Also, there are a number of studies regarding the measurement of laminar and transitional boundary-layer flows, distribution of the mean velocity and the profiles of mean and fluctuating velocities $[27,28]$. 
It is very clear from the literatures that there is no availability of aerodynamic data for corner-edged square cylinder at low Re. Hence, the present work is carried out numerically to study the effect of corner radius on drag and boundary layer within a range of Reynolds number $5 \leq \operatorname{Re} \leq 45$ with different corner radii $(r=050,0.51$, $0.54,0.59,0.64$ and 0.71$)$. So far, to the best of the authors' knowledge, this kind of study is the first of its kind within the considered criteria. The main purpose of the present work is (i) to obtain the knowledge about the boundarylayer profile for a corner-edged square cylinder and (ii) also to obtain the effect of corner radius on the drag and boundary layer. A brief review of the current computational configuration is discussed in sections $2-5$. Section 6 provides a brief discussion about the numerical results.

\section{Geometrical configuration}

The aim here is to study the behaviour of the flow past a square cylinder with rounded corner edges placed in a channel on the centre-line (figure 1). The square cylinder of side $D$ and non-dimensional radius of corner $r(R /$ $D=0.50,0.51,0.54,0.59,0.64$ and 0.71 ) is held in a rectangular channel and steady laminar flow of $x$-velocity, $u=U_{\infty}$ (free-stream velocity), flows over the body. The distance of the upstream and the downstream boundaries from the centre of the cylinder are $L_{\mathrm{u}}=10 D$ and $L_{\mathrm{d}}=40 D[15,17,29,30]$, respectively. The details of the domain independence study are discussed in section 5 . The distance between the upper and lower side-walls, $H$, is specified according to the blockage ratio $(D / H=0.05)$ to make the flow confined [1].

\section{Mathematical formulation}

For the incompressible, two-dimensional steady laminar flow across the square cylinder with rounded cornered edges, the dimensionless forms of the continuity and the $x$ and $y$ components of the Navier-Stokes equation in a rectangular co-ordinate system are given here.Continuity equation:

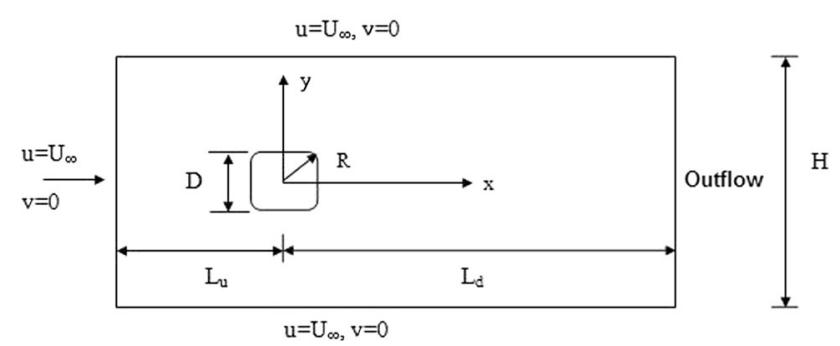

Figure 1. A schematic diagram of the present problem.

$$
\frac{\partial u}{\partial x}+\frac{\partial v}{\partial y}=0
$$

$x$-momentum equation:

$$
\frac{\partial u u}{\partial x}+\frac{\partial v u}{\partial y}=-\frac{\partial p}{\partial x}+\frac{1}{\operatorname{Re}}\left(\frac{\partial^{2} u}{\partial x^{2}}+\frac{\partial^{2} u}{\partial y^{2}}\right),
$$

$y$-momentum equation:

$$
\frac{\partial u v}{\partial x}+\frac{\partial v v}{\partial y}=-\frac{\partial p}{\partial y}+\frac{1}{\operatorname{Re}}\left(\frac{\partial^{2} v}{\partial x^{2}}+\frac{\partial^{2} v}{\partial y^{2}}\right)
$$

where $\operatorname{Re}=\frac{\rho U_{\infty} D}{\mu}$ is the Reynolds Number. The viscous and pressure forces acting on the cylinder are used to calculate the drag, lift and pressure coefficients.

The drag coefficient is given as

$$
C_{D}=\frac{F_{D}}{0.5 \rho U_{\infty}^{2} D},
$$

where $F_{\mathrm{D}}$ is the drag force acting on the cylinder.

The pressure coefficient is a parameter for studying the flow of incompressible fluids such as water and also the low-speed flow of compressible fluid such as air. The relationship between the dimensionless coefficient and the dimensional variables is given as

$$
C_{p}=\frac{p-p_{\infty}}{0.5 \rho U_{\infty}^{2}},
$$

where $p$ is the pressure at the point at which pressure coefficient is being evaluated.

Using Bernoulli's equation, the pressure coefficient can be further simplified for incompressible, lossless and steady flow:

$$
C_{p}=1-\left(\frac{V}{U_{\infty}}\right)^{2}
$$

where $V$ is the velocity of the fluid at the point at which pressure coefficient is being evaluated.

\section{Boundary conditions}

The physical boundary conditions for the configuration discussed earlier are written as follows:

- The left wall of the computational domain is designed as the inlet. The 'velocity inlet' boundary condition is assigned at the inlet boundary with free-stream velocity $U_{\infty}$.

- The usual no-slip boundary condition is assigned for flow at the surface of the cylinder, i.e., $u=0 ; v=0$.

- The usual slip boundary condition is assigned at the upper and lower surface of the computational domain, i.e., $u=U_{\infty} ; v=0$. 
- The extreme right surface of the computational domain is assigned as an outlet. At the 'outflow' boundary, the diffusion fluxes in the direction normal to the exit surface are zero for all variables, i.e., $\left(\frac{\partial u}{\partial x}=0, \frac{\partial v}{\partial x}=0, \frac{\partial \theta}{\partial x}=0\right)$ is assigned.

\section{Numerical methodology}

\subsection{Grid structure and grid independence study}

The grid distribution of the computational domain used in the present investigation is shown in figure 2 .

It is observed from figure 2, that a non-uniform grid structure for the whole computational domain is assigned. Grids are generated using the grid generation package GAMBIT. An expanded view of the central block of the computational domain having the cylinder is shown in figure $2 \mathrm{~b}$. The central block that contains the cylinder has a fine mesh to adequately capture the wake-wall interactions in both directions and the grids become coarser non-uniformly towards the boundary wall.

In this study, three different mesh sizes (Grid1 - 15,000, Grid2 - 25,000 and Grid3 - 40,000) are adopted in order to check the mesh independence. A detailed grid independence study has been performed on the cylinder with $r=0.64$ and results are obtained for the bubble length $\left(L_{r}\right)$ and drag coefficient $\left(C_{\mathrm{d}}\right)$ but there are no considerable changes between Grid 2 and Grid3 (the results are presented in table 1). Thus, a grid size of 25,000 is found to meet the requirements of both grid independence and computation time limit.
Table 2. Domain independence study at $r=0.64$ and $\operatorname{Re}=40$.

\begin{tabular}{|c|c|c|c|c|}
\hline & $C_{\mathrm{d}}$ & $\begin{array}{l}\text { Percentage } \\
\text { change }\end{array}$ & $L_{r}$ & $\begin{array}{c}\text { Percentage } \\
\text { change }\end{array}$ \\
\hline \multicolumn{5}{|c|}{$L_{\mathrm{u}}\left(\right.$ at $\left.L_{\mathrm{d}}=40 D\right)$} \\
\hline $5 D$ & 1.7515 & - & 2.643 & - \\
\hline $10 D$ & 1.7175 & 1.98 & 2.700 & 2.10 \\
\hline $15 D$ & 1.7116 & 0.34 & 2.689 & 0.42 \\
\hline \multicolumn{5}{|c|}{$L_{\mathrm{d}}\left(\right.$ at $\left.L_{\mathrm{u}}=10 D\right)$} \\
\hline $20 D$ & 1.7331 & - & 2.711 & - \\
\hline $30 D$ & 1.7158 & 1.01 & 2.701 & 0.38 \\
\hline $40 D$ & 1.7175 & 0.1 & 2.700 & 0.03 \\
\hline
\end{tabular}

Further, a detailed domain independence study has been accomplished with the purpose of having optimized downstream distance $\left(L_{\mathrm{d}}\right)$ and upstream distance $\left(L_{\mathrm{u}}\right)$. A number of hit and miss combinations of $L_{\mathrm{u}}$ and $L_{\mathrm{d}}$ were examined by taking an initial value of $L_{\mathrm{u}}=10 \mathrm{D}$ and $L_{\mathrm{d}}=40 D[15,16,29,30]$ and the results are itemized in table 2. After evaluating the effect of domain length on the $C_{\mathrm{d}}$ and $L_{r}$, the value of $L_{\mathrm{u}}$ and $L_{\mathrm{d}}$ is selected as $10 D$ and $40 D$, respectively.

\subsection{Numerical details}

In the present investigation, the numerical simulation is performed using the finite-volume-based commercial CFD solver Ansys FLUENT 6.3. FLUENT is used to solve the governing equations, which are partial differential equations, using the control-volume-based technique in a (a)

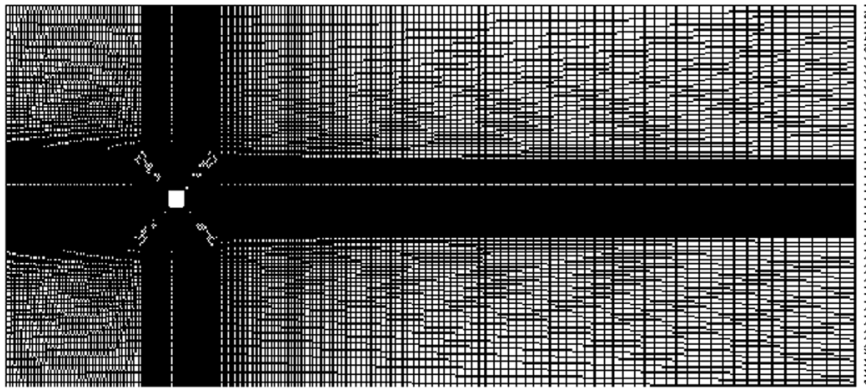

(b)

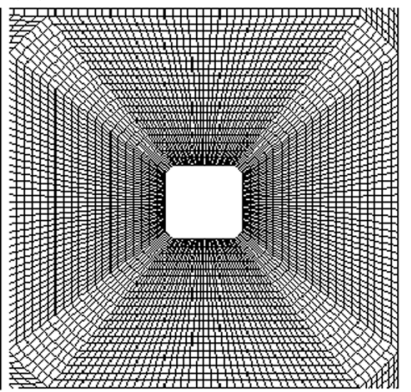

Figure 2. (a) Grid distribution of the computational domain and (b) zoomed view of the grid distribution of the cylinder.

Table 1. Study of effect of grid size for grid independence test.

\begin{tabular}{|c|c|c|c|c|c|c|c|c|}
\hline \multirow[b]{2}{*}{$\begin{array}{l}\text { No. of } \\
\text { cells }\end{array}$} & \multicolumn{4}{|c|}{$\operatorname{Re}=10$} & \multicolumn{4}{|c|}{$\mathrm{Re}=40$} \\
\hline & $L_{r}$ & $\begin{array}{l}\text { Percentage change } \\
\text { of } L_{r}\end{array}$ & $C_{\mathrm{d}}$ & $\begin{array}{l}\text { Percentage change } \\
\text { of } C_{\mathrm{d}}\end{array}$ & $L_{r}$ & $\begin{array}{l}\text { Percentage change } \\
\text { of } L_{r}\end{array}$ & $C_{\mathrm{d}}$ & $\begin{array}{c}\text { Percentage change } \\
\text { of } C_{\mathrm{d}}\end{array}$ \\
\hline 15,000 & 0.470 & - & 3.1011 & - & 2.550 & - & 1.6125 & - \\
\hline 25,000 & 0.500 & 6.38 & 3.2635 & 5.24 & 2.700 & 5.55 & 1.7175 & 6.51 \\
\hline 40,000 & 0.501 & 0.20 & 3.2745 & 0.34 & 2.702 & 0.07 & 1.7211 & 0.21 \\
\hline
\end{tabular}


Table 3. Comparison of $L_{r}$ and $C_{\mathrm{d}}$ with the published literature values for $r=0.71$ (square).

\begin{tabular}{|c|c|c|c|c|c|c|c|c|c|c|}
\hline & \multicolumn{2}{|c|}{$\operatorname{Re}=5$} & \multicolumn{2}{|c|}{$\operatorname{Re}=10$} & \multicolumn{2}{|c|}{$\operatorname{Re}=20$} & \multicolumn{2}{|c|}{$\operatorname{Re}=30$} & \multicolumn{2}{|c|}{$\operatorname{Re}=40$} \\
\hline & $L_{r}$ & $C_{\mathrm{d}}$ & $L_{r}$ & $C_{\mathrm{d}}$ & $L_{r}$ & $C_{\mathrm{d}}$ & $L_{r}$ & $C_{\mathrm{d}}$ & $L_{r}$ & $C_{\mathrm{d}}$ \\
\hline Dhiman et al [3] & - & 4.840 & 0.49 & 3.63 & 1.05 & 2.44 & 1.62 & 1.99 & 2.17 & 1.75 \\
\hline Breuer et al [32] & - & - & 0.49 & 3.64 & 1.04 & 2.50 & 1.60 & 2.00 & 2.15 & 1.70 \\
\hline Gupta et al [4] & - & - & 0.40 & 3.51 & 0.90 & 2.45 & 1.40 & 2.06 & 1.90 & 1.86 \\
\hline Present study & - & 4.716 & 0.50 & 3.52 & 1.10 & 2.42 & 1.67 & 2.02 & 2.20 & 1.79 \\
\hline
\end{tabular}

collected grid system. The solver used in the present work is a pressure-based implicit method. Semi-Implicit Method for Pressure-Linked Equation (SIMPLE) is selected for the pressure-velocity coupling scheme. The pressure term is discretized under the scheme of STANDARD, whereas the momentum is discretized by a second-order upwind scheme. The laminar viscous model is used for the low Reynolds numbers. The convergence criteria for the continuity and velocity are set to $10^{-5}$.

\section{Results and discussion}

Results are presented for two-dimensional computations for the range of Reynolds number $5 \leq \mathrm{Re} \leq 45$ and non-dimensional corner radius of $0.50,0.51,0.54,0.59,0.64$ and 0.71 .

\subsection{Validation of present results}

Since the present work is carried out numerically, it is required to validate the present method with the published available data. Hence, the validation is done with both the square $(r=0.71)$ and circular $(r=0.5)$ cylinders of published experimental and numerical results. A comparison of the present investigation with the published results at $\operatorname{Re}=10,20,30$ and 40 shown is shown in tables 3 and 4 . Further, the present results are also validated with the round cornered cylinders data of Jaiman et al [31] and the discrepancy is depicted in figure 3 . The current results are in excellent agreement with those published data.

\subsection{Boundary layer and displacement thickness}

The boundary-layer thickness, $\delta$, is the distance across a boundary layer from the wall to a point where the flow velocity is $99 \%$ of the free-stream velocity. The velocity $u(y)$ is the velocity at the point perpendicular to the cylinder upper surface, which has zero velocity at $y=0$ and increase along the perpendicular distance up to $u(y)=U_{\infty}$. The displacement thickness, $\delta^{*}$, is the distance by which a surface would have to be moved in the direction perpendicular to its normal vector away from the reference plane in an inviscid fluid stream of velocity to give the same flow
Table 4. Comparison of $C_{\mathrm{d}}$ with the published literature values for $r=0.5$ (circular).

\begin{tabular}{lcccc}
\hline & \multicolumn{5}{c}{$C_{\mathrm{d}}$} \\
\cline { 2 - 5 } & $\mathrm{Re}=10$ & $\mathrm{Re}=20$ & $\mathrm{Re}=30$ & $\mathrm{Re}=40$ \\
\hline $\begin{array}{c}\text { Tritton [33] } \\
\text { (experimental) }\end{array}$ & - & 2.22 & - & 1.48 \\
$\begin{array}{c}\text { Fornberg [34] } \\
\text { (numerical) }\end{array}$ & - & 2.00 & - & 1.50 \\
$\begin{array}{c}\text { Present study } \\
\text { (numerical) }\end{array}$ & 3.22 & 2.24 & 1.75 & 1.51 \\
\hline
\end{tabular}

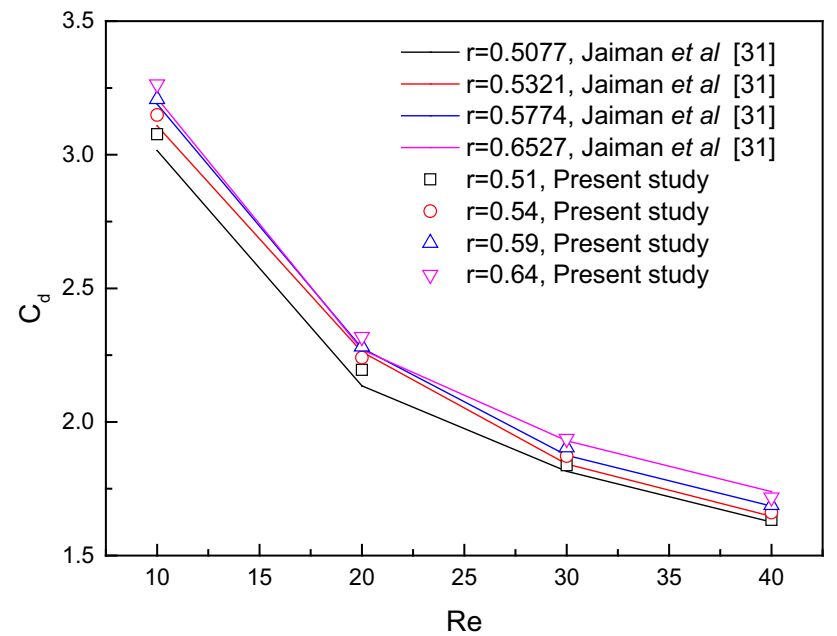

Figure 3. Discrepancy of the drag coefficient of present study with the earlier results.

rate as occurs between the surface and the reference plane in a real fluid [35].

The variations of the boundary layer thickness and displacement thickness with respect to Re for various corner radii $(r=0.50,0.51,0.54,0.59,0.64$ and 0.71$)$ are shown in figure $4 \mathrm{a}$ and $\mathrm{b}$, respectively. These figures also reveal the novel equations relating the $\delta$ and $\delta^{*}$ with Re. The displacement thickness is calculated at a distance of $H / 4$ from the centre of the computational domain. Figure $4 \mathrm{a}$ and b shows that the $\delta$, as well as $\delta^{*}$, increases when $r$ is increased but decreases when Re is increased, which is mainly due to the strong pressure gradient and weak wall 

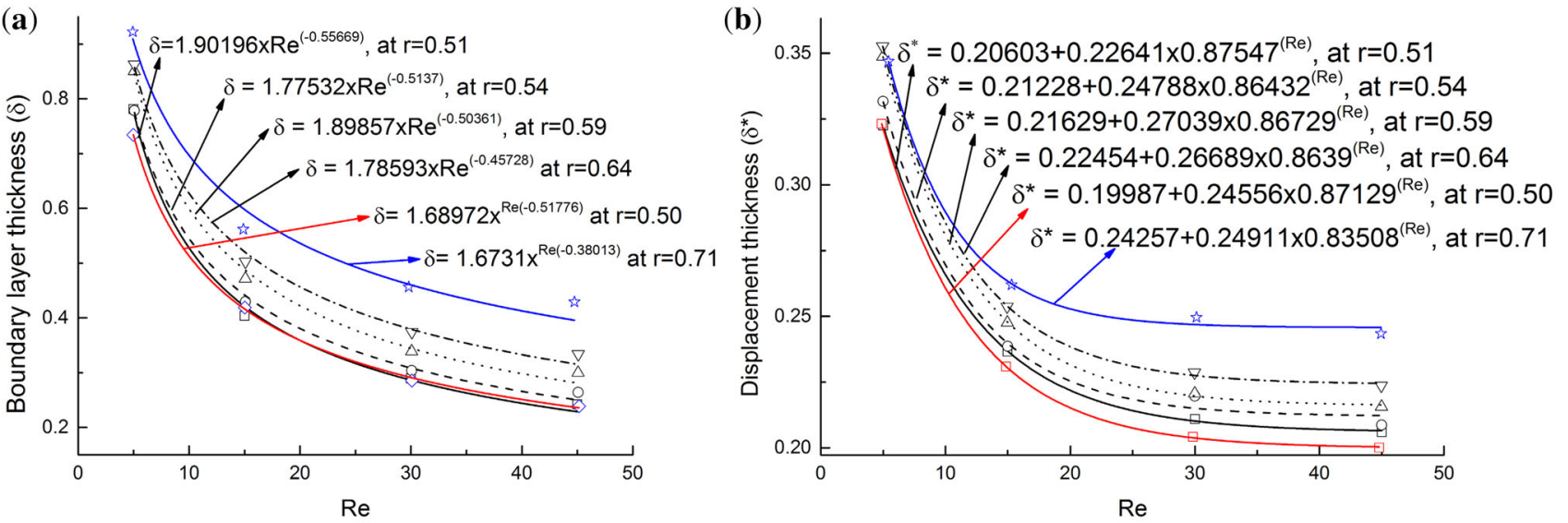

(c)

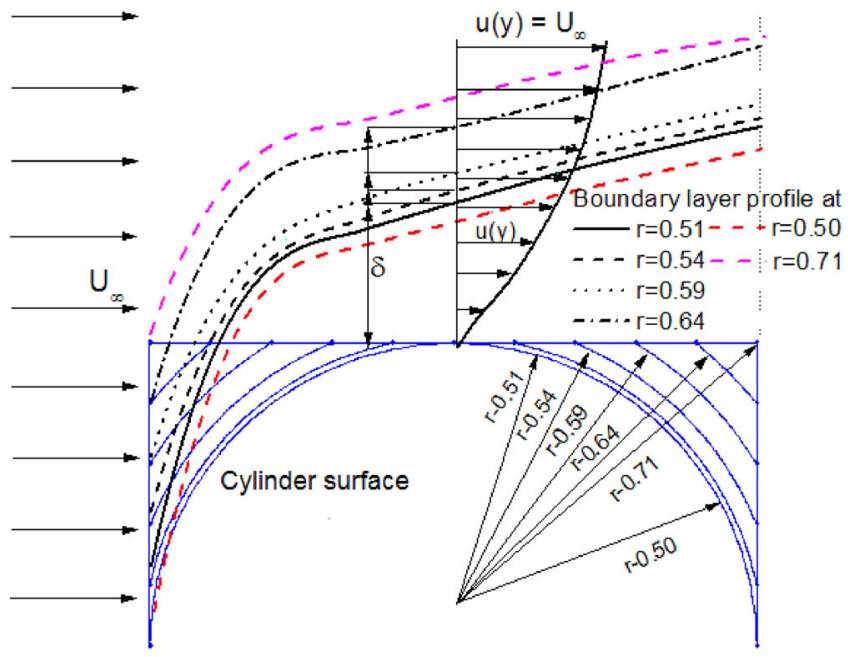

Figure 4. (a) Variation of boundary-layer thickness with Re, (b) variation of displacement thickness with Re and (c) boundary-layer profile above upper cylinder surface at $r=0.51,0.54,0.59$ and 0.64 for $\operatorname{Re}=45$.

shear stress. The boundary-layer profiles for square cylinder with different corner radii $(r=0.51,0.54,0.59$ and 0.64$)$ are shown in figure $4 \mathrm{c}$, which are self-explanatory for such a kind of cylinder model. It is evident from figure $4 \mathrm{c}$ that the velocity profile shifts vertically upward with the increment of the corner radius. For $r=0.50,0.51,0.54$ and 0.59 , the boundary layer profiles are close to each other, compared with the boundary layer profile at $r=0.64$ and $r=0.71$. The higher the position of boundary layer, stronger the adverse pressure gradient. In the same figure, velocity profile of $u$ with respect to vertical reference line $(y)$ is shown. It shows that at the wall surface, $u(y)=0$ and it increases vertically until it reaches the velocity of free stream. Further discussion about the velocity profile of $u(y)$ is depicted in figure 5 .

The velocity profiles of $u(y)$ at different corners and for different Re are shown in figure 5. It is evident from the figures that when the radius of the corner increases, the curvature of the profile decreases towards the vertical line (at $x=0$ ). It reveals the characteristics of the cylinder, i.e., if it is more curved in the corners it leads to smoother layers and larger continuity of the fluid layers. Also, the closeness of the curvature becomes larger on increasing the Re, which divulges that at higher Re the flow becomes less steady. This phenomenon occurs mainly due to the wall shear stress developed by the flow over the cylinder, which reduces with the increment of Re as well as corner radius. Also, it shows the features of the direction of flow due to the change of the cylinder shape and Re.

Figure 6 shows the boundary-layer profile over the cylinder for different corner radii at $\operatorname{Re}=5,15$ and 30. It is clearly depicted that when corner radius increases, the boundary layer profile shifts upwards for every Re (shown in figures $4 \mathrm{c}$ and $6 \mathrm{a}-\mathrm{c}$ ). For a particular $r$ (say $r=0.64$ ) and different $\operatorname{Re}$ (shown in figure $6 \mathrm{~d}$ ), the profile is shifted downwards when Re is increased. In laminar flow, the fluid moves in smooth and parallel layers. There is relatively little mixing and consequently the velocity gradients are 
(a)
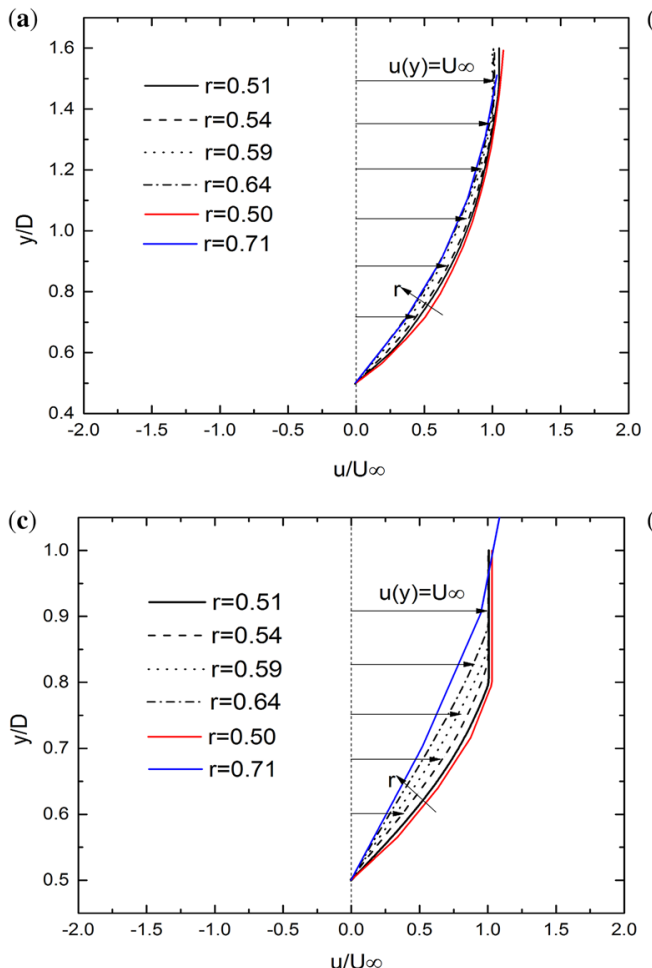

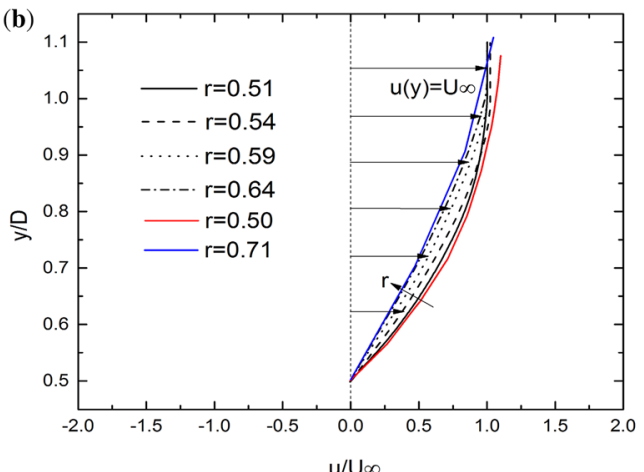

(d)

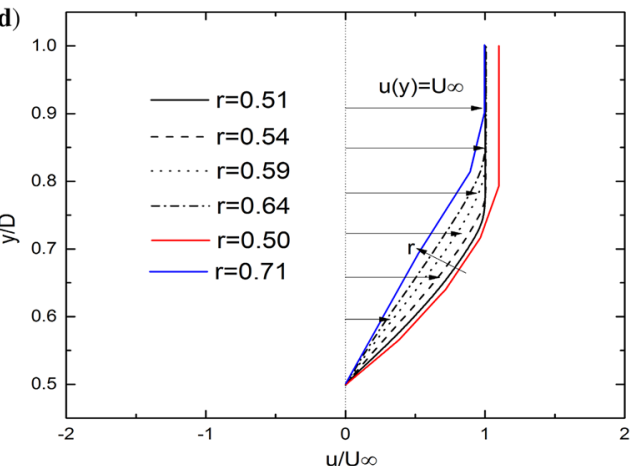

Figure 5. Velocity profile as a function of $y$ at (a) $\operatorname{Re}=5$, (b) $\operatorname{Re}=15$, (c) $\operatorname{Re}=30$ and (d) $\operatorname{Re}=45$.
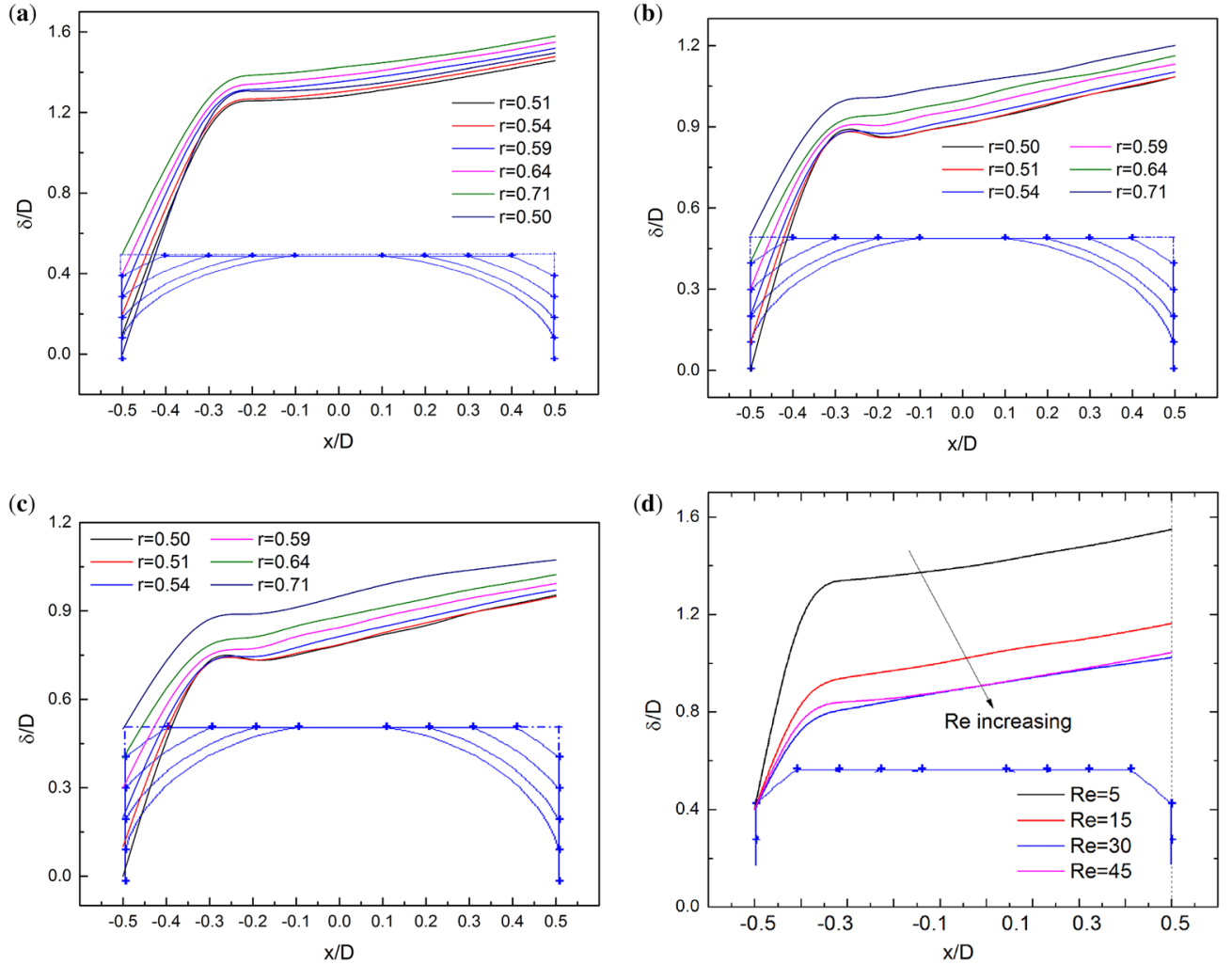

Figure 6. Boundary-layer profile at (a) $\operatorname{Re}=5,(\mathbf{b}) \operatorname{Re}=15$ and (c) $\operatorname{Re}=30$ for $r=0.50,0.51,0.54,0.59,0.64$ and 0.71 and (d) at $r=0.64$ for $\operatorname{Re}=5,15,30$ and 45 . 
(a)

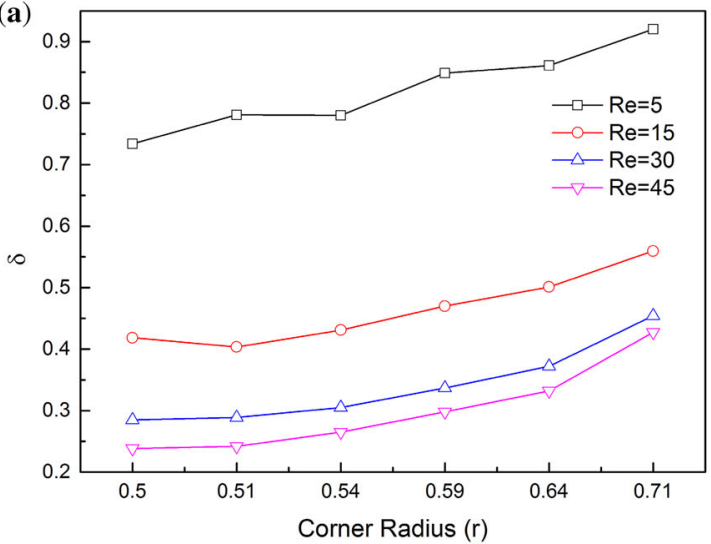

(b)

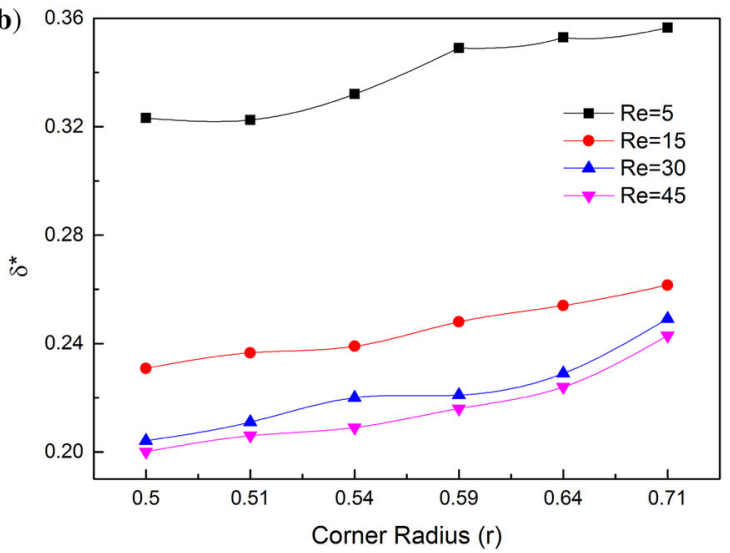

Figure 7. Effect of corner radius on (a) boundary layer thickness and (b) displacement thickness.

(a)
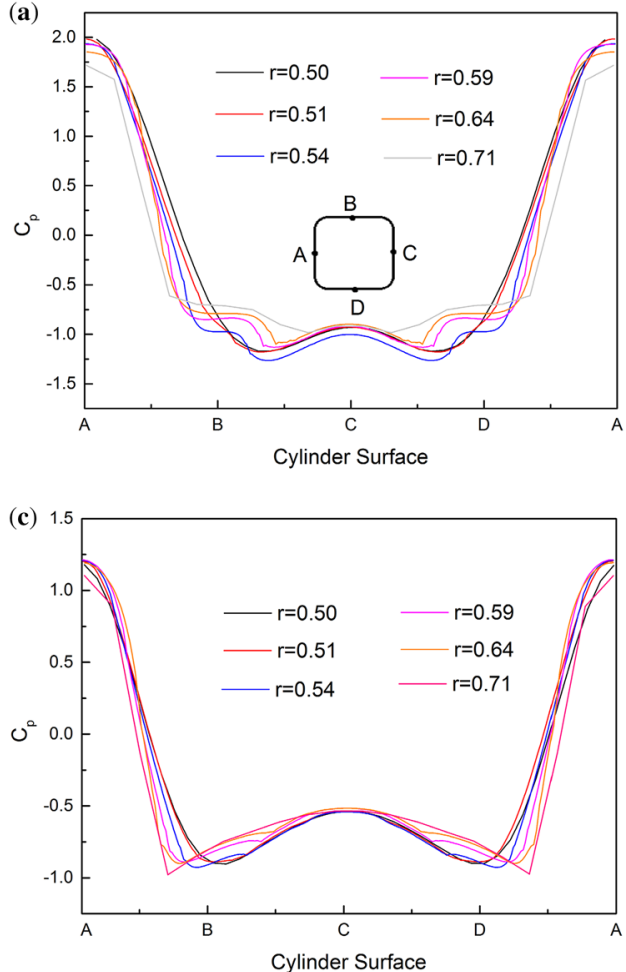

(b)

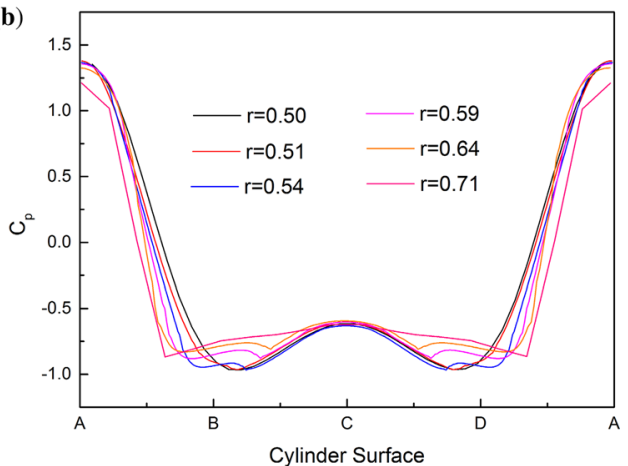

(d)

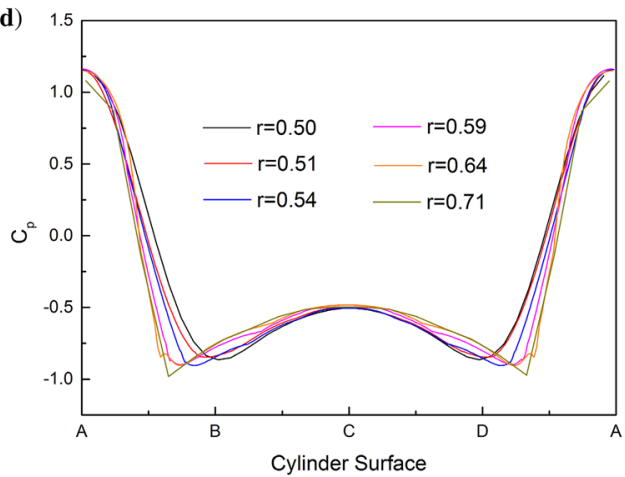

Figure 8. Variation of coefficient of pressure for $(\mathbf{a}) \operatorname{Re}=5,(\mathbf{b}) \operatorname{Re}=15,(\mathbf{c}) \operatorname{Re}=30$ and $(\mathbf{d}) \operatorname{Re}=45$.

small and shear stresses are low. Higher the corner radius, higher the distance of velocity profile from the cylinder surface, which is obviously the reason for less smoothness of the fluid striking the surface of the cylinder. Due to this the thickness of the laminar boundary layer increases with distance from the start of the boundary layer and decreases with Reynolds number. The characteristics of boundary layer thickness and displacement thickness for different Re and corner radii are depicted in figure $7 \mathrm{a}$ and $\mathrm{b}$. The value of $\delta^{*}$ linearly increases with the increment of corner radius, which reveals that larger values of corner radius create larger skin friction on the surface.

Some further information on the nature of the flow can be gained by examining the pressure coefficient variation with Re at different corner radii, which is shown in figure 8 . The pressure distribution on the cylinder surface at different points is shown in figure $8 \mathrm{a}-\mathrm{d}$. Larger variation has been seen between 

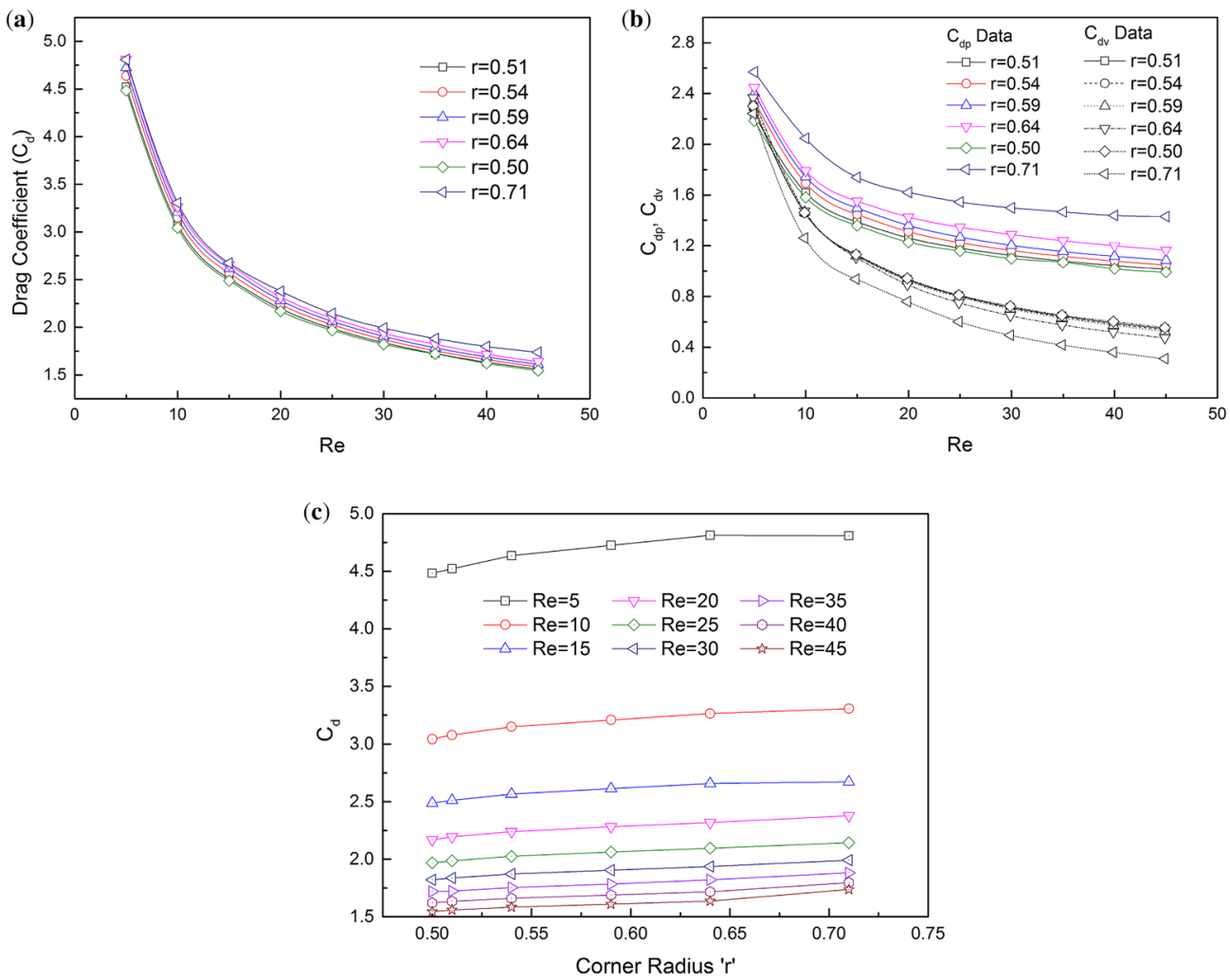

Figure 9. Variation of (a) drag coefficient with Re, (b) pressure drag coefficient and viscous drag coefficient with Re and (c) drag coefficient with corner radius.

$\mathrm{Re}=5$ and 45 for different corner radii at the corner of the cylinder. At the midpoint of the cylinder front surface (towards the upstream) the value of $C_{\mathrm{p}}$ is nearly equal for all the corner radii, which is mainly because that point is not affected by the corner. Whatever the corner ratio, the position of the point remains the same for the entire configuration.

\subsection{Variation of drag coefficient with $R e$ and $r$}

The variation of the drag coefficient with Reynolds number at various corner ratios is shown in figure 9a. It is observed from the figure that the drag coefficient of a bluff body decreases sharply with the increase of Re within the range of $5 \leq \operatorname{Re} \leq 45$. Due to the increasing pressure recovery at the cylinder base, the decrease in $C_{\mathrm{d}}$ is achieved. This figure also indicates that $C_{\mathrm{d}}$ increases with the increment of the corner radius, which means that the forward movement of the cylinder is enhanced with the corner ratio. This reduction in $C_{\mathrm{d}}$ is mainly due to the smaller frontal area of the cylinder, and also the curved surfaces are more efficient in dispersing the flowing fluid to strike at the front surface. Also, the velocity of the body through the fluid becomes larger when the corner radius is smaller and makes the cylinder more aerodynamic. Figure $9 \mathrm{~b}$ and $\mathrm{c}$ presents the variation of pressure and viscous drag component, which shows that both are nearly parallel to each other for all configurations.

It has also been observed that at low Re, there is less variation of viscous force values and the effect on drag. This characteristic is due to the smaller change in the velocity of the body through the fluid at low Re.

The figure also reveals the relative dominance of the pressure drag over its viscous counterpart [36].

Figures 10 and 11 illustrate the visualization of streamline contour for $\mathrm{Re}=5$ and 45 at different corner radii $(r=0.51,0.54,0.59$ and 0.64$)$. It is clearly visualized that at $\operatorname{Re}=5$, there is no development of wake, whereas at $\operatorname{Re}=45$ the wake is fully developed behind the cylinder for every corner radius. It is found that when Re increases the drag is minimized, and also it is noticeable that at higher Re there is a formation of wake. Combining both of these phenomena, we can conclude that the wake may reduce the drag by introducing some motion opposite to the drag. This generation of wakes at higher Re is mainly raised as a result of adverse pressure gradients at the top and rear parts of the cylinder.

\subsection{Skin friction coefficient with Re and $r$}

Figure 12 shows the value of the skin friction coefficient on the cylinder surface. Skin friction coefficient $\left(C_{\mathrm{f}}\right)$ is nothing 
(a)

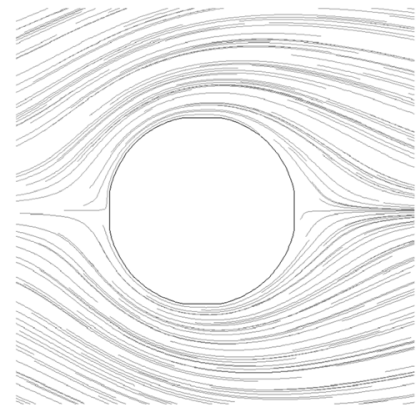

(b)

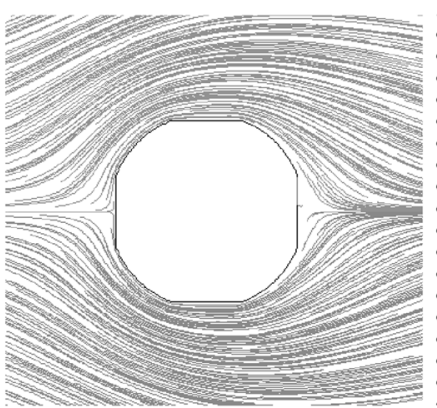

(c)

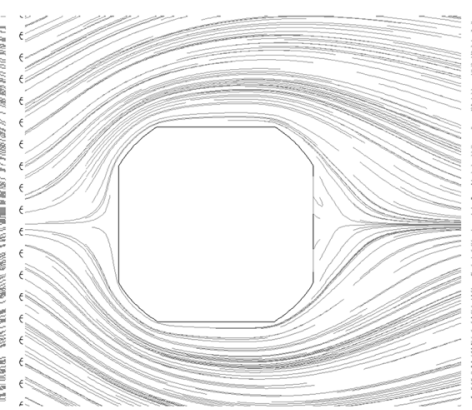

(d)

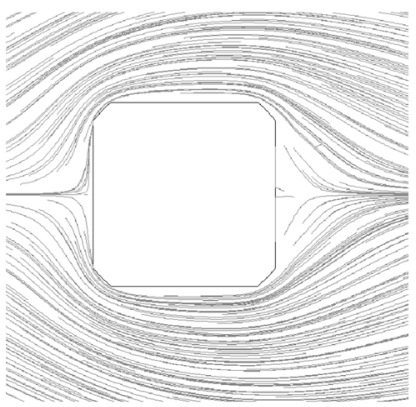

Figure 10. Streamline contour at $\operatorname{Re}=5$ for (a) $r=0.51$, (b) $r=0.54$, (c) $r=0.59$ and (d) $r=0.64$.

(a)

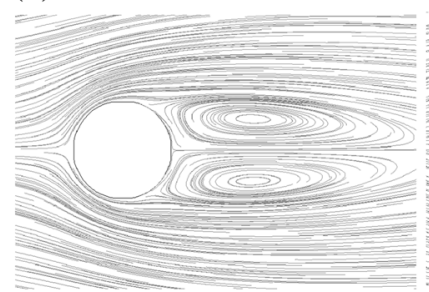

(b)

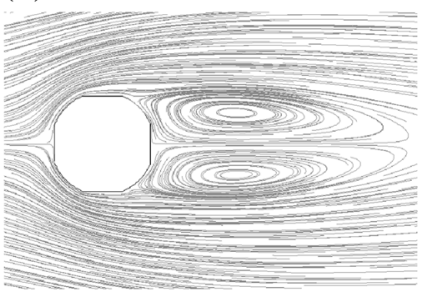

(c)

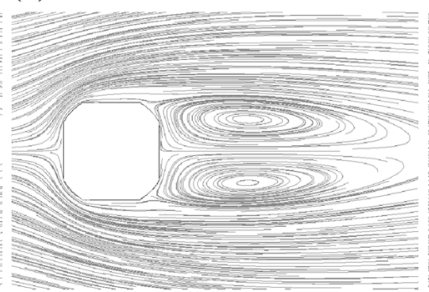

(d)

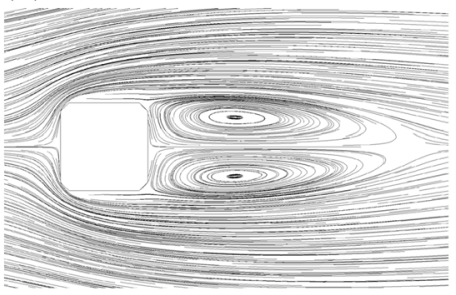

Figure 11. Streamline contour at $\operatorname{Re}=45$ for (a) $r=0.51$, (b) $r=0.54$, (c) $r=0.59$ and (d) $r=0.64$.

(a)

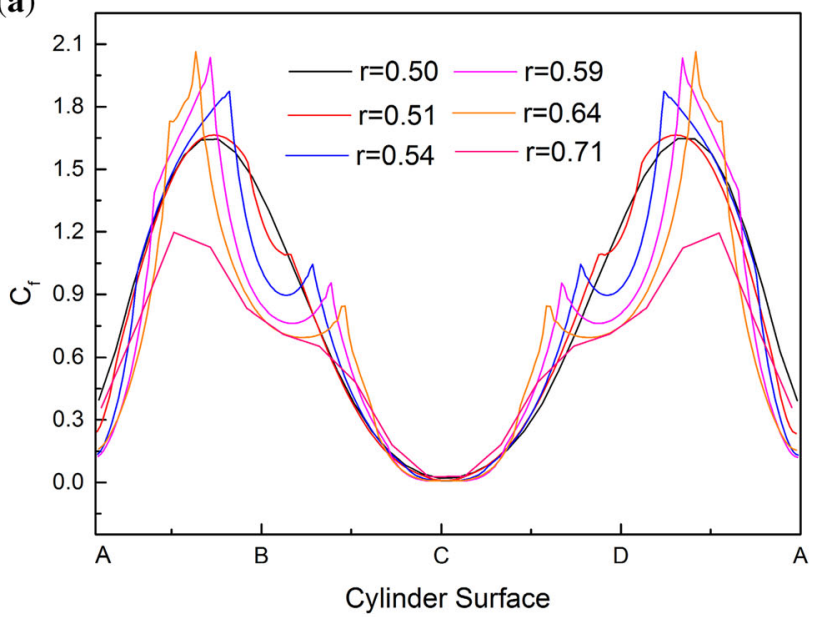

(b)

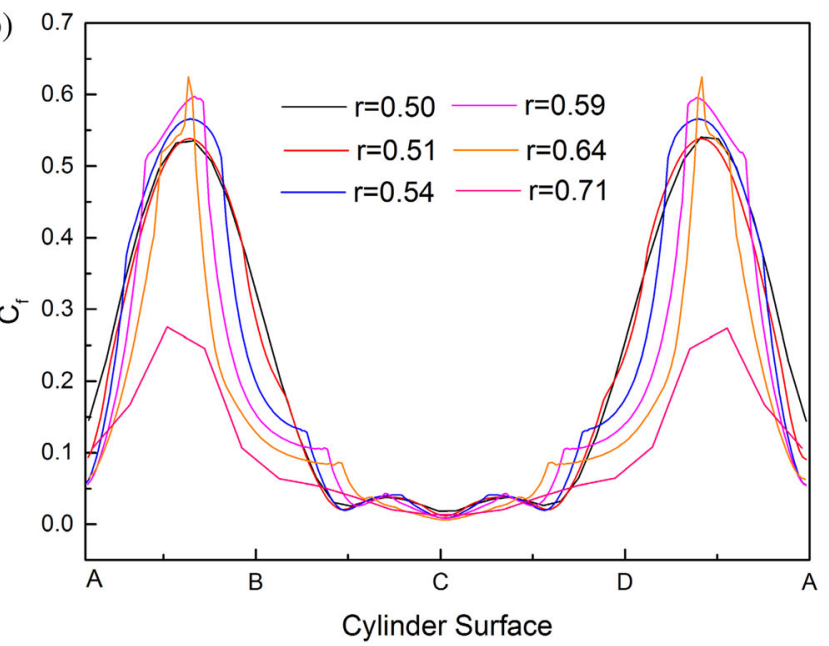

Figure 12. Variation of skin friction coefficient for (a) $\operatorname{Re}=5$ and (b) $\operatorname{Re}=45$.

but the non-dimensional form of shear stress developed on the surface, or it can be also expressed in terms of drag force. It is clearly evident from figure 12 that at higher $\mathrm{Re}$ and for every arc ratio, the value of $C_{\mathrm{f}}$ on the cylinder surface decreases.

As the $\mathrm{Re}$ increases, the value of $C_{\mathrm{f}}$ decreases, which implies that at higher Re and for every arc ratio, there is a reduction of shear stress, which is due to the reduction of the contact zone. This contact zone is due to the attachment of fluid molecules to the surface of the cylinder. This reduction of $C_{\mathrm{f}}$ is also due to the small-scale structure of flow in the boundary layer. At the forward stagnation point, $\mathrm{B}$, the value of $C_{\mathrm{f}}$ is minimum for all configurations (shown in figure 12), which states that at point B, the shear stress and $C_{\mathrm{d}}$ both are minimum due to the minimum contact surface with fluid since the fluid separates from that point. In figure 12, there are sudden pick points on the values. These pick points are only on the rounded edges, where the 
contact between fluid molecules and the surfaces becomes large and creates more friction.

\section{Conclusion}

Steady laminar fluid flow over a square cylinder with rounded edges (which is more aerodynamic as compared with a square) over a range of Reynolds number, 5-45 (to keep the flow as steady as possible), for different corner radii $(0.50,0.51,0.54,0.59,0.64$ and 0.71$)$ has been numerically studied in this paper. By the present numerical study, it has been found that the boundary-layer thickness $(\delta)$ and displacement thickness $\left(\delta^{*}\right)$ are directly proportional to ' $r$ ' and inversely proportional to 'Re'. This characteristic is due to the strong pressure gradient and weak wall shear stress developed around the cylinder. Also, when the corner radius is decreased, the cylinder becomes more aerodynamic due to the reduction of the pressure and viscous forces acting on the cylinder. The drag coefficient is inversely proportional to Re and directly proportional to the corner radius. At lower corner radius, the value is minimum, which implies that when the shape of a square cylinder is gradually converted to circular, it becomes more aerodynamic.

\section{List of symbols}

$B \quad$ blockage ratio $(D / H)$

$C_{\mathrm{d}} \quad$ coefficient of drag (dimensionless)

$C_{\mathrm{L}} \quad$ coefficient of lift (dimensionless)

$C_{\mathrm{p}} \quad$ pressure coefficient (dimensionless)

$C_{\mathrm{dp}}$ pressure component of drag coefficient

$C_{\mathrm{dv}} \quad$ viscous component of drag coefficient

$D \quad$ width of the square cylinder (m)

$F_{\mathrm{D}} \quad$ drag force acting on the cylinder $(\mathrm{N} / \mathrm{m})$

$F_{\mathrm{L}} \quad$ lift force acting on the cylinder $(\mathrm{N} / \mathrm{m})$

$L_{\mathrm{d}} \quad$ downstream face distance of the inlet from the cylinder centre $(\mathrm{m})$

$L_{\mathrm{u}} \quad$ upstream face distance of the inlet from the cylinder centre $(\mathrm{m})$

Re Reynolds number $\left(=\frac{\rho U_{\infty} D}{\mu}\right)$ (dimensionless)

$U_{\infty}$ free-stream velocity $(\mathrm{m} / \mathrm{s})$

$x, y \quad$ Cartesian coordinates

$p_{\infty} \quad$ free-stream pressure

$R$ radius of corner $(\mathrm{m})$

$r \quad$ radius of corner (dimensionless, $R / D$ )

$u, v$ velocity components in $x$ and $y$ directions $(\mathrm{m} / \mathrm{s})$

\section{Greek symbols}

$\rho \quad$ density $\delta \quad$ boundary layer thickness

$\delta^{*} \quad$ displacement thickness

\section{References}

[1] Sen S, Mittal S and Biswas G 2009 Steady separated flow past a circular cylinder at low Reynolds numbers. J. Fluid Mech. 620: 89-119

[2] Bhattacharyya S and Mahapatra S 2005 Vortex shedding around a heated square cylinder under the influence of buoyancy. Heat Mass Transf. 41(9): 824-833

[3] Dhiman A, Chhabra R and Eswaran V 2005 Flow and heat transfer across a confined square cylinder in the steady flow regime: effect of Peclet number. Int. J. Heat Mass Transf. 48(21): 4598-4614

[4] Gupta A K et al 2003 Two-dimensional steady flow of a power-law fluid past a square cylinder in a plane channel: momentum and heat-transfer characteristics. Ind. Eng. Chem. Res. 42(22): 5674-5686

[5] Ji T H, Kim S Y and Hyun J M 2008 Experiments on heat transfer enhancement from a heated square cylinder in a pulsating channel flow. Int. J. Heat Mass Transf. 51(5): $1130-1138$

[6] Rahnama M and Hadi-Moghaddam H 2005 Numerical investigation of convective heat transfer in unsteady laminar flow over a square cylinder in a channel. Heat Transf. Eng. 26(10): 21-29

[7] Sahu A K, Chhabra R and Eswaran V 2009 Effects of Reynolds and Prandtl numbers on heat transfer from a square cylinder in the unsteady flow regime. Int. J. Heat Mass Transf. 52(3): 839-850

[8] Sheard G J, Fitzgerald M J and Ryan K 2009 Cylinders with square cross-section: wake instabilities with incidence angle variation. J. Fluid Mech. 630: 43-69

[9] Dey P and Das A Steady flow over triangular extended solid attached with square cylinder-a method to reduce drag. Ain Shams Eng. J. 6(3): 929-938

[10] Dey P and Das A 2015 Numerical analysis of drag and lift reduction of square cylinder. Eng. Sci. Technol. Int. J. 18(4): $758-768$

[11] Golani R and Dhiman A 2014 Fluid flow and heat transfer across a circular cylinder in the unsteady flow regime. Int. J. Eng. Sci. 3(3): 08-19

[12] Mahír N and Altaç Z 2008 Numerical investigation of convective heat transfer in unsteady flow past two cylinders in tandem arrangements. Int. J. Heat Fluid Flow 29(5): $1309-1318$

[13] Posdziech O and Grundmann R 2007 A systematic approach to the numerical calculation of fundamental quantities of the two-dimensional flow over a circular cylinder. J. Fluids Struct. 23(3): 479-499 
[14] Shi J M et al 2004 Heating effect on steady and unsteady horizontal laminar flow of air past a circular cylinder. Phys. Fluids 16(12): 4331-4345

[15] Dey P and Das A 2016 A utilization of GEP (gene expression programming) metamodel and PSO (particle swarm optimization) tool to predict and optimize the forced convection around a cylinder. Energy 95: 447-458

[16] Dey P, Sarkar A and Das A K 2015 Prediction of unsteady mixed convection over circular cylinder in the presence of nanofluid-a comparative study of ANN and GEP. J. Naval Architect. Mar. Eng. 12(1): 57-71

[17] Dey P, Sarkar A and Das A K 2016 Development of GEP and ANN model to predict the unsteady forced convection over a cylinder. Neural Comput. Appl. 27(8): 2537-2549

[18] Kwok K, Wilhelm P and Wilkie B 1988 Effect of edge configuration on wind-induced response of tall buildings. Eng. Struct. 10(2): 135-140

[19] Tamura T and Miyagi T 1999 The effect of turbulence on aerodynamic forces on a square cylinder with various corner shapes. J. Wind Eng. Ind. Aerodyn. 83(1): 135-145

[20] Hu J, Zhou Y and Dalton C 2006 Effects of the corner radius on the near wake of a square prism. Exp. Fluids 40(1): 106-118

[21] Mandal A and Faruk G 2010 An experimental investigation of static pressure distributions on a group of square or rectangular cylinders with rounded corners. J. Mech. Eng. 41(1): 42-49

[22] Carassale L, Freda A and Marrè-Brunenghi M 2013 Effects of free-stream turbulence and corner shape on the galloping instability of square cylinders. J. Wind Eng. Ind. Aerodyn. 123: $274-280$

[23] Carassale L, Freda A and Marrè-Brunenghi M 2014 Experimental investigation on the aerodynamic behavior of square cylinders with rounded corners. J. Fluids Struct. 44: 195-204

[24] Ozalp A A and Dincer I 2010 Hydrodynamic-thermal boundary layer development and mass transfer characteristics of a circular cylinder in confined flow. Int. J. Therm. Sci. 49(9): 1799-1812
[25] Ozalp A A and Dincer I 2010 Laminar boundary layer development around a circular cylinder: fluid flow and heatmass transfer characteristics. J. Heat Transf. 132(12): 121703

[26] Lin P and Zhang W 2008 Numerical simulation of waveinduced laminar boundary layers. Coast. Eng. 55(5): 400-408

[27] Zhang D, Winoto S and Chew Y 1995 Measurement in laminar and transitional boundary-layer flows on concave surface. Int. J. Heat Fluid Flow 16(2): 88-98

[28] Görtler H 1954 On the three-dimensional instability of laminar boundary layers on concave walls. NACA

[29] Dey P and Das A 2016 Prediction and optimization of unsteady forced convection around a rounded cornered square cylinder in the range of Re. Neural Comput. Appl. pp. 1-11 doi: 10.1007/s00521-015-2168-5

[30] Dey P and Das A 2016 Numerical analysis and prediction of unsteady forced convection over a sharp and rounded edged square cylinder. J. Appl. Fluid Mech. 9(3): 1189-1199

[31] Jaiman R K, Sen S and Gurugubelli P S 2015 A fully implicit combined field scheme for freely vibrating square cylinders with sharp and rounded corners. Comput. Fluids 112: 1-18

[32] Breuer M et al 2000 Accurate computations of the laminar flow past a square cylinder based on two different methods: lattice-Boltzmann and finite-volume. Int. J. Heat Fluid Flow 21(2): 186-196

[33] Tritton D J 1959 Experiments on the flow past a circular cylinder at low Reynolds numbers. J. Fluid Mech. 6(4): 547-567

[34] Fornberg B 1980 A numerical study of steady viscous flow past a circular cylinder. J. Fluid Mech. 98(04) 819-855

[35] Schlichting H and Gersten K 2000 Boundary-layer theory. Berlin: Springer

[36] Sen S, Mittal S and Biswas G 2011 Flow past a square cylinder at low Reynolds numbers. Int. J. Num. Methods Fluids 67(9): 1160-1174 